\title{
Adherence to GOLD guidelines in real-life COPD management in the Puglia region of Italy
}

This article was published in the following Dove Press journal: International Journal of COPD

\author{
Giuseppe Antonio Palmiotti,' \\ Donato Lacedonia, 'Vito \\ Liotino, ${ }^{2}$ Pietro Schino, ${ }^{3}$ \\ Francesco Satriano, ${ }^{4}$ Pier Luigi \\ Di Napoli, ${ }^{3}$ Eugenio Sabato, ${ }^{5}$ \\ Vincenzo Mastrosimone, ${ }^{6}$ \\ Alfredo Scoditti, ${ }^{7}$ Mauro \\ Carone, ${ }^{8}$ Elio Costantino, ${ }^{9}$ \\ Emanuela Resta, ${ }^{2}$ Ettore \\ Attolini, ${ }^{10}$ Maria Pia Foschino \\ Barbaro'
}

'Department of Medical and Surgical Sciences, Institute of Respiratory Diseases, University of Foggia, Foggia, Italy; ${ }^{2}$ Department of Cardiac, Thoracic, and Vascular Science, Institute of Respiratory Diseases, School of Medicine, University of Bari, Bari, Italy; ${ }^{3}$ Physiopathology Respiratory Unit, F Miulli General Hospital, Acquaviva delle Fonti, Bari, Italy; ${ }^{4}$ Pneumology Clinic, Vito Fazzi Hospital, Lecce, Italy; ${ }^{5} \mathrm{UOC}$ of Pneumology, "N Melli” Hospital, San Pietro Vernotico, Italy; ${ }^{6}$ Division of Pulmonary Disease, Medical Center of Rehabilitation, Foundation Salvatore Maugeri, IRCCS, Marina di Ginosa, Italy; ${ }^{7}$ Department of Respiratory Diseases, San Camillo Clinic, Taranto, Italy; ${ }^{8}$ Division of Pulmonary Disease, Medical Center of Rehabilitation, Foundation Salvatore Maugeri, IRCCS, Cassano delle Murge, Italy; 'UOC of Pneumology, Hospital "Madonna delle Grazie", Matera, Italy; ${ }^{10}$ Regional Health Agency (ARES), Bari, Italy
Correspondence: Giuseppe Antonio Palmiotti Institute of Respiratory Diseases, Department of Medical and Surgical Sciences, University of Foggia, viale deglia viatori 7I I22, Foggia, Italy

Tel +39 088I $733 \quad$ l 40

Fax +39 088I 733040

Email antoniopalmiotti@hotmail.it
Background: COPD is a disease associated with significant economic burden. It was reported that Global initiative for chronic Obstructive Lung Disease (GOLD) guideline-oriented pharmacotherapy improves airflow limitation and reduces health care costs. However, several studies showed a significant dissociation between international recommendations and clinicians' practices. The consequent reduced diagnostic and therapeutic inappropriateness has proved to be associated with an increase in costs and a waste of economic resources in the health sector. The aim of the study was to evaluate COPD management in the Puglia region. The study was performed in collaboration with the pulmonology centers and the Regional Health Agency (AReS Puglia).

Methods: An IT platform allowed the pulmonologists to enter data via the Internet. All COPD patients who visited a pneumological outpatient clinic for the first time or for regular follow-ups or were admitted to a pneumological department for an exacerbation were considered eligible for the study. COPD's diagnosis was confirmed by a pulmonologist at the moment of the visit. The project lasted 18 months and involved 17 centers located in the Puglia region.

Results: Six hundred ninety-three patients were enrolled, evenly distributed throughout the region. The mean age was $71 \pm 9$ years, and $85 \%$ of them were males. Approximately $23 \%$ were current smokers, $63 \%$ former smokers and $13.5 \%$ never smokers. The mean post-bronchodilator forced expiratory volume in 1 second was $59 \% \pm 20 \%$ predicted. The platform allowed the classification of patients according to the GOLD guidelines (Group A: 20.6\%, Group B: 32.3\%, Group C: 5.9\% and Group D: $39.2 \%)$, assessed the presence and severity of exacerbations (20\% of the patients had an exacerbation defined as mild [13\%], moderate [37\%] and severe [49\%]) and evaluated the appropriateness of inhalation therapy at the time of the visit. Forty-nine percent of Group A patients were following inappropriate therapy; in Group B, $45.8 \%$ were following a therapy in contrast with the guidelines. Among Group C patients, $41.46 \%$ resulted in triple combination therapy, while $\sim 14 \%$ of Group D patients did not have a therapy or were following an inappropriate therapy. In conclusion, $30 \%$ of all patients evaluated had been following an inadequate therapy. Subsequently, an online survey was developed to inquire about the reasons for the results obtained. In particular, we investigated the reasons why $30 \%$ of our population did not follow the therapy suggested by the GOLD guidelines: 1) why was there an excessive use of inhaled corticosteroids, 2) why a significantly high percentage was inappropriately treated with triple therapy and 3) why a consistent percentage (11\%) of Group D patients were not treated at all.

Conclusion: The data provides an overview on the management of COPD in the region of Puglia (Italy) and represents a resource in order to improve appropriateness and reduce the waste of health resources.

Keywords: COPD, appropriateness, web platform, health care spending, online survey

\section{Introduction}

COPD is a disease associated with a significant economic burden. In the European Union, the total direct costs of respiratory diseases are estimated to be $6 \%$ of the 
total health care budget, with COPD accounting for $56 \%$ (38.6 billion euros) of the cost of respiratory diseases. ${ }^{1}$ In particular, exacerbations of COPD represent the greatest burden on health care spending ${ }^{2}$ due to accelerated decline in lung function, ${ }^{3}$ impaired quality of life, ${ }^{4}$ hospitalization ${ }^{5}$ and increased mortality. ${ }^{6}$

Current international recommendations for $\mathrm{COPD}^{7}$ propose long-acting inhaled bronchodilators (BDs), including long-acting $\beta 2$-agonists (LABA) and long-acting muscarinic antagonists (LAMA), on a regular basis as monotherapy or in combination with inhaled corticosteroids (ICS) for the symptomatic management of COPD and the prevention of exacerbations. ${ }^{8-11}$

A report from the Observatory on the Use of Medicines (OsMed, 2016) states that drugs used for the respiratory system are the 17 th therapeutic category with high public spending in Italy, amounting to $\sim 828.7$ million euro (13.7 euro per capita). ${ }^{12}$ Tiotropium, salmeterol and formoterol are present in the top 30 drugs that contribute most to the public health expenditure. In Italy alone, $13.4 \%$ of the patients aged $\geq 40$ years was found adherent to treatment with medications for obstructive airway syndromes in $2016 .^{12}$

Although many studies emphasize that Global initiative for chronic Obstructive Lung Disease (GOLD) guidelineoriented pharmacotherapy is associated with an improvement of airflow limitation and with a reduction in health care cost, ${ }^{13,14}$ a significant dissociation has been reported between recommendations and clinicians' practices, ${ }^{15}$ and this could influence the appropriateness of prescribing therapy in COPD. Several studies showed a suboptimal adherence to the GOLD guidelines in different patient cohorts, often with overprescription of ICS. These studies have shown that by improving adherence, direct and indirect costs are reduced. ${ }^{16,17}$

In this context, this project was developed as a collaboration between the University of Foggia and the Regional Health Agency (AReS Puglia) with the aim to improve the uniformity of COPD management within the territory in order to ensure better diagnostic and therapeutic appropriateness and provide policy makers with useful information for the implementation of appropriate regional health policy measures. Puglia is a region in southern Italy with a population of $\sim 4$ million people divided into 6 provinces. According to data collected in 2007, it is estimated that, in the $>40$-yearold population, the prevalence of COPD is $\sim 7 \%$, equivalent to $\sim 150,000$ patients, with high prevalence in the provinces of Brindisi, Lecce and Taranto. Starting from the GOLD guidelines, the Regional Health Agency had adopted its own
"Diagnostic, Therapeutic and Assistance Plan" (PDTA) for the management of patients with COPD. This work has verified the use of the guidelines and the utility of PDTA.

\section{Methods}

This study was designed and developed by a collaboration among the Regional Health Agency of Puglia, major hospitals and territorial pneumological centers of the region.

It is an observational, cross-sectional, non-interventional multicentre study carried out from May 1, 2015 to December 31, 2016, which involved 17 centers evenly distributed throughout the territory. The protocol was centrally approved by the Regional Health Agency (ARES - D.DR.G. 05/2015). All patients provided written informed consent to participate in the study. All COPD patients who visited a pneumological outpatient clinic for the first time or for regular follow-ups or were admitted to a pneumological department for an exacerbation were considered eligible for the study. The subjects were registered in the electronic Case Report Form (e-CRF). e-CFR was characterized by questions that could be answered either through the numerical insertion in already pre-established intervals or flagging the desired answer in appropriate drop-down menus. This allowed us to homologate the answers and the data obtained and to minimize the bias related to the insertion of data by the operators. In each unit, one or more specialists filled out an e-CRF with clinical information on patients with a confirmed diagnosis of COPD. The e-CRF required the following basic information: demographic data, history of smoking, history of exacerbations, history of influenza and pneumococcal vaccinations, data about comorbidities, pre- and post-BD spirometry data, presence and severity of exacerbation at the moment of the visit and therapy prescribed, radiological pattern at Rx or CT scan, assessment of symptoms through validated questionnaires COPD Assessment Test (CAT) and Modified Medical Research Council (mMRC) and current pharmacotherapy.

All the e-CRFs were sent online to the central database for data processing and analysis. The identity of all patients was kept anonymous.

According to GOLD 2015, the COPD diagnosis was based on clinical history, physical examination and spirometric evaluation (forced expiratory volume in 1 second $\left[\mathrm{FEV}_{1}\right]$ / FVC $<70 \%$ after BDs). The degree of severity of COPD was established using the values of the $\mathrm{FEV}_{1} \%$ predicted, history of exacerbations and severity of symptoms by the CAT and mMRC as follows:

1) less symptoms (CAT $<10$ and $\mathrm{mMRC}<2)$, low risks $(<2$ exacerbations/year, $\mathrm{FEV}_{1}>50 \%$ ) 
2) more symptoms (CAT $>10$ and $\mathrm{mMRC}>2)$, low risks $\left(<2\right.$ exacerbations/year, $\mathrm{FEV}_{1}>50 \%$ )

3) less symptoms $(\mathrm{CAT}<10$ and $\mathrm{mMRC}<2)$, high risks ( $>2$ exacerbations/year, $\mathrm{FEV}_{1}<50 \%$ )

4) more symptoms (CAT $>10$ and $m M R C>2)$, high risks $\left(>2\right.$ exacerbations/year, $\mathrm{FEV}_{1}<50 \%$ ).

The medical treatment of COPD at the moment of the visit was recorded. The appropriateness of the pharmacological treatment of COPD patients and the type of inappropriateness were established in accordance with the GOLD guidelines. $^{7}$

1) First choice: SABA or SAMA. Alternative choice: SABA + SAMA or LAMA or LABA.

2) First choice: LAMA or LABA. Alternative choice: LAMA + LABA.

3) First choice: ICS/LABA or LAMA. Alternative choice: LAMA + LABA or LABA + inhibitor of phosphodiesterase 4 or LAMA + inhibitor of phosphodiesterase 4 .

4) First choice: ICS/LABA and/or LAMA. Alternative choice: LAMA + LABA or ICS/LABA + inhibitor of phosphodiesterase 4 or LAMA + inhibitor of phosphodiesterase 4 .

At the end of the study, participants were asked to respond to an online survey. The aim of the survey was to evaluate the motivation of the obtained results and the feasibility of the IT platform.

\section{Ethical approval}

All procedures performed in the studies involving human participants were in accordance with the ethical standards of the institutional and/or national research committee and with the 1964 Declaration of Helsinki and its later amendments or comparable ethical standards. The study was approved by the Regional Health Agency (AReS Puglia) dated January 23, 2015. Informed consent was obtained from all individual participants included in the study.

\section{Results}

Six hundred ninety-three patients were enrolled, evenly distributed throughout the territory. The participating centers were divided as follows: 2 university hospital centers, 8 community hospital centers and 7 territorial outpatient facilities. The number of patients recruited by type amounted to $39 \%$ in university hospitals, $32.5 \%$ in community hospitals and $28.5 \%$ in territorial outpatient facilities. The characteristics of the patient population are shown in Table 1.

Approximately $13.56 \%$ of patients had never been smokers, while $23.3 \%$ were smokers and $63.2 \%$ were former smokers. COPD exacerbation history was $\geq 2$ occurrences in $34.7 \%$ of the population, while $65.3 \%$ had $<2$ exacerbations per year. Exacerbation management revealed that $18.3 \%$ required hospitalization, while $81.7 \%$ were managed

Table I General characteristics of subjects

\begin{tabular}{|c|c|c|c|c|}
\hline & Mean & Min & Max & $\begin{array}{l}\text { Standard } \\
\text { deviation }\end{array}$ \\
\hline$N(M / F)$ & \multicolumn{4}{|l|}{$693(589 / 104)$} \\
\hline Age, years & 71 & 4I & 95 & 9 \\
\hline BMI & 28.08 & 14.69 & 57.27 & 5.68 \\
\hline Smoker, former smoker, or never smoker, $\mathrm{n}(\%)$ & \multicolumn{4}{|l|}{161 (23.3), 438 (63.20), 94 (13.56) } \\
\hline Pack-year & 35.15 & 0.00 & 210.00 & 33.93 \\
\hline FEV $\%$ & 59.08 & 16 & 115 & 20.13 \\
\hline FVC\% & 79.08 & 21 & 144 & 21.46 \\
\hline $\mathrm{FEV}_{1} / \mathrm{FVC}$ & 55.84 & 19.00 & 70.00 & 10.81 \\
\hline CAT & 15.53 & 0.00 & 39.00 & 8.59 \\
\hline mMRC & 2.92 & 1.00 & 5.00 & 1.15 \\
\hline Barthel scale & 18.64 & 6.00 & 20.00 & 2.64 \\
\hline$<2$ exacerbations/year, $\mathrm{n}(\%)$ & $452(65.30)$ & & & \\
\hline$\geq 2$ exacerbations/year, $\mathrm{n}(\%)$ & $24 I(34.70)$ & & & \\
\hline Vaccination influenza virus, $\mathrm{n}(\%)$ & $316(45.70)$ & & & \\
\hline Vaccination pneumococcus, $\mathrm{n}(\%)$ & $164(23.80)$ & & & \\
\hline \multicolumn{5}{|l|}{ GOLD classification, $\mathrm{n}(\%)$} \\
\hline $\mathrm{A}$ & $142(20.60)$ & & & \\
\hline $\mathrm{B}$ & $238(32.30)$ & & & \\
\hline C & $4 \mathrm{I}(5.90)$ & & & \\
\hline $\mathrm{D}$ & $272(39.20)$ & & & \\
\hline
\end{tabular}

Abbreviations: Min, minimum; Max, Maximum; M, male; F, female; BMI, body mass index; FEV ${ }_{\text {, }}$ forced expiratory volume in I second; FVC, forced vital capacity; GOLD, Global initiative for chronic Obstructive Lung Disease. 
with the use of antibiotics and corticosteroids at home. At the moment of the visit, $20 \%$ of the patients showed an exacerbation defined as mild (13\%), moderate (37\%) and severe $(49 \%)$. We also evaluated the presence of comorbidities in the study population. The most represented were as follows: chronic ischemic heart disease $22 \%$, obesity $21 \%$, type 2 diabetes $17.6 \%$, chronic heart failure $13.8 \%$, gastroesophageal reflux $7.8 \%$, osteoporosis $6 \%$, depression $4.4 \%$, pulmonary hypertension $4.2 \%$, cognitive decline $2.8 \%$ and lung cancer $2 \%$.

Of the 693 patients, 422 had a radiological assessment available. In particular, $132(31.3 \%)$ showed a predominantly emphysematous pattern, $205(48.5 \%)$ a predominantly bronchitic pattern and $85(20.2 \%)$ a mixed pattern. We also investigated vaccination coverage for influenza virus and pneumococcus: $45.7 \%$ of the patients had been vaccinated for the flu virus while $23.8 \%$ for pneumococcus.

Regarding the questionnaires on symptom assessment, we found that $27.4 \%$ had a CAT $<10$ and $62.9 \% \geq 10$, while $7.7 \%$ had an mMRC $<2$ and $83.6 \% \geq 2$.

With these data, the "ABCD" assessment was performed according to the GOLD guidelines in use at the moment of the study. ${ }^{7}$ Group A represented $20.6 \%$ of patients, Group B $32.3 \%$, Group C 5.9\% and Group D 39.2\% of the study population. We could also discriminate if patients were at high risk of exacerbations (Groups C-D) for the history of exacerbations (42.1\%), the spirometric impairment $(25.8 \%)$ or both $(32.1 \%)$.

Regardless of the assessment of severity of COPD, the most widely used inhaled medications in the territory are LAMA 500 (72.6\%), LABA 464 (67.3\%) and ICS 343 (49.8\%). Only 6 patients $(0.9 \%)$ used phosphodiesterase 4 inhibitors, while $126(18.3 \%)$ patients used a mucoregulator and 37 patients $(5.3 \%)$ used theophylline.

Finally, we evaluated the appropriateness of inhalation therapy at the time of the visit (Table 2 and Figure 1).

We found that $49.3 \%$ of Group A patients were following inappropriate therapy, with a surprising $14.08 \%$ already in triple therapy (ICS/LABA + LAMA); in Group B, $45.8 \%$ were following a therapy in contrast with guidelines. Among Group C patients, $41.46 \%$ received triple therapy, while $\sim 14 \%$ of the Group D patients did not have a therapy or were following an inappropriate therapy. Thus, $\sim 30 \%$ of the patients evaluated had been following a therapy that was different from the one suggested by guidelines or were not treated at all (Table 3 and Figure 2). The results of the survey are summarized in Table 4: in particular, pulmonologists in the Puglia region think that the $30 \%$ of discrepancy is due to the fact that GOLD recommendations are far from reality $(60 \%)$; "ABCD model" is difficult to routinely use because spirometry is not always feasible (40\%) and increases the length of time of the visit $(30 \%)$; the excessive use of corticosteroids is due to the information received from pharmaceutical companies (50\%) and secondarily because corticosteroids are more effective than proven in clinical trials (30\%); the inappropriate use of triple therapy is due to the belief that it guarantees better and faster results on the patient's symptoms (35\%) and is easier to prescribe than double bronchodilation alone (40\%); finally, the general medical practitioner $(45 \%)$ and patients $(40 \%)$ underestimate the disease causing $11 \%$ of Group D patients to not be treated.

\section{Discussion}

The data provide an overview on the management of COPD in the region of Puglia (Italy) and give the opportunity to make many considerations.

First of all, $-30 \%$ of the patients analyzed were following a different therapy with respect to GOLD recommendations despite the fact that adherence to the pharmacological management, recommended in the GOLD document, has been shown to improve patient outcomes and reduce health care costs. ${ }^{13}$ The degree of inappropriateness affects Groups $\mathrm{A}, \mathrm{B}$ and $\mathrm{C}$ in equal measure and less in Group D. In fact, the tendency in Puglia is to provide the maximum therapy

Table 2 Ongoing therapy at the first visit (Figure I)

\begin{tabular}{|c|c|c|c|c|c|}
\hline Therapy & ALL & Group A* & Group B* & Group C* & Group D* \\
\hline None, n (\%) & $69(9.96)$ & $15(10.56)$ & $19(7.98)$ & $5(12.20)$ & $30(11.03)$ \\
\hline LABA, n (\%) & $19(2.74)$ & $6(4.23)$ & $7(2.94)$ & I (2.44) & $\mathrm{I}(\mathrm{I} .84)$ \\
\hline LAMA, n (\%) & 124 (I7.89) & $44(30.99)$ & 49 (20.59) & $9(21.95)$ & $22(8.09)$ \\
\hline LABA + ICS, n (\%) & $103(14.86)$ & $23(16.20)$ & $47(19.75)$ & $2(4.88)$ & $50(\mid 8.38)$ \\
\hline LAMA + LABA, n (\%) & $125(18.04)$ & 27 (19.0I) & $28(11.76)$ & $7(17.07)$ & $44(16.18)$ \\
\hline ICS + LAMA + LABA, n (\%) & $228(32.90)$ & $20(14.08)$ & $81(34.03)$ & $17(4 \mid .46)$ & $110(40.44)$ \\
\hline Other therapies, n (\%) & $25(3.6 \mathrm{I})$ & $7(4.93)$ & $7(2.94)$ & $0(0.00)$ & II (4.04) \\
\hline Total, n (\%) & $693(100)$ & $142(100)$ & $238(100)$ & $41(100)$ & $272(100)$ \\
\hline
\end{tabular}

Notes: *GOLD classification.

Abbreviations: GOLD, Global initiative for chronic Obstructive Lung Disease; LABA, long-acting $\beta 2$-agonists; LAMA, Long-acting muscarinic antagonist; ICS, inhaled corticosteroids. 


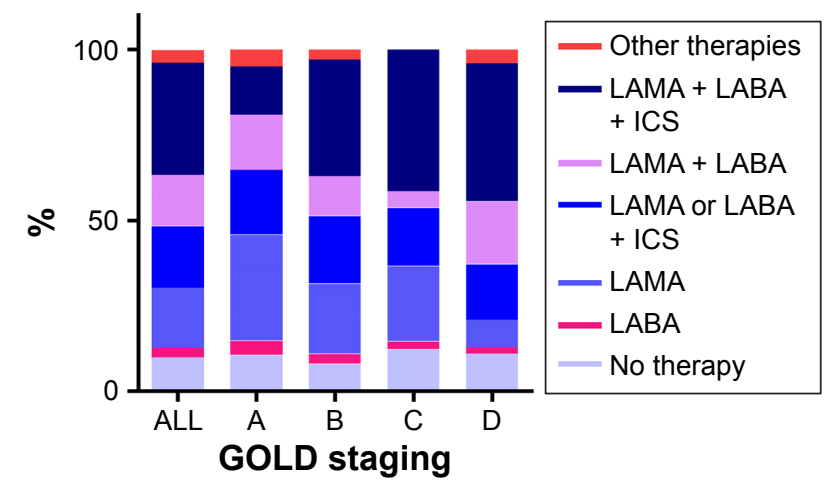

Figure I Ongoing therapy at the first visit.

Abbreviations: LABA, long-acting $\beta 2$-agonists; LAMA, long-acting muscarinic antagonist; ICS, inhaled corticosteroids.

to all patients, regardless of the degree of severity of the disease. Many studies have demonstrated that subjects with COPD continue to be treated incorrectly, suggesting that the guidelines are not being fully utilized. ${ }^{18}$ This is a common problem not only in other areas in Italy, as demonstrated by Corrado and Rossi in a study in $2012,{ }^{35}$ but it is also an international issue. ${ }^{16-19}$

The lack of adherence to clinical guidelines may be due to several barriers, some of which are physician-related, such as lack of awareness, non-familiarity, outcome of expectancy, time constraints and non-agreement with recommendations. Other barriers are patient-related, environmental and guidelinerelated factors, which are beyond the control of physicians. ${ }^{20}$

We tried to find the reasons for these discrepancies by asking the opinion of the participants of the study through an online survey. Our pulmonologists agree that the guidelines are far from reality, and the ABCD model is difficult to apply. An explanation could be that, of the 17 participating centers, approximately one-third is represented by territorial outpatient facilities that are often not adequately equipped. In our region, according to a recent census, there are $\sim 36$ public and private hospitals and outpatient facilities in which a pneumologist is present, which equals $\sim 150$ members. Of these, $76.6 \%$ (93 members) are $>40$ years old. Conversely, the 2 centers with the greatest number of patients included in the database are university centers in which the presence of greater economic and human resources (trainee doctors) allows for better adherence to the GOLD guidelines.

Other findings of our survey are related to the excessive use of ICS and inappropriate use of triple therapy (ICSLABA-LAMA). The problem of overprescription of ICS is described by several papers in the literature. ${ }^{32-34}$ Repetition of the drugs formerly given by another pulmonologist without a careful assessment is described to be one of the reasons. ${ }^{21}$ The higher preference for combination devices, including ICS/LABA rather than ICS and LABA in separate devices, may also cause the overprescription of medication including ICS. ${ }^{19}$ In our case, information received from pharmaceutical companies represents the main reason. Desalu et $\mathrm{al}^{22}$ in their work claimed that the widespread use of LABA/ICS combination may be explained by its longer marketing history and better availability in the public health care system, contributing to a much higher utilization rate than LAMA or LABA monotherapy. The second reason for overprescription of ICS is the belief that they are more effective. This is supported by international literature, in an editorial, Sin and Man in 2010 made the questionable suggestion that "A more plausible (and simple) explanation (for the high worldwide sales of combined ICS/LABA) is that clinicians (and patients) use ICS-based therapy for COPD because they work". ${ }^{23}$ Instead the excessive use of the triple therapy is justified by the fact that it is easier to prescribe than double bronchodilation.

This paradox is explained considering that it is necessary to compile a therapeutic plan to prescribe a LAMA-LABA in a single device every 6 months. While if LAMA and an ICS-LABA are prescribed separately, this problem does not occur, since a therapeutic plan is not necessary for either of them. This reduces bureaucratic tasks and visiting time.

Finally, our pulmonologists agree that general practitioners and patients underestimate the disease resulting in $11 \%$ of patients in Group D not being treated at all. While the understanding perception of COPD among general practitioners is a problem already known and described in the literature, ${ }^{24}$ according to a DOXA analysis (an institution

Table 3 Assessment of the degree of therapeutic appropriateness of the total study population and classified by severity classes in relation to the GOLD 2015 guidelines (Figure 2A-D)

\begin{tabular}{llllll}
\hline & ALL & Group A* & Group B* & Group C* & Group D* \\
\hline In line with GL, n (\%) & $419(60.46)$ & $57(40.14)$ & $110(46.22)$ & $18(43.9)$ & $234(86.03)$ \\
Not in line with GL, n (\%) & $205(29.58)$ & $70(49.30)$ & $109(45.80)$ & $18(43.9)$ & $8(2.94)$ \\
No therapy, n (\%) & $69(9.96)$ & $15(10.56)$ & $19(7.98)$ & $5(12.20)$ & $30(11.03)$ \\
Total, n (\%) & $693(100)$ & $142(100)$ & $238(100)$ & $41(100)$ & $272(100)$ \\
\hline
\end{tabular}

Notes: *GOLD classification.

Abbreviations: GL, guideline; GOLD, Global initiative for chronic Obstructive Lung Disease. 


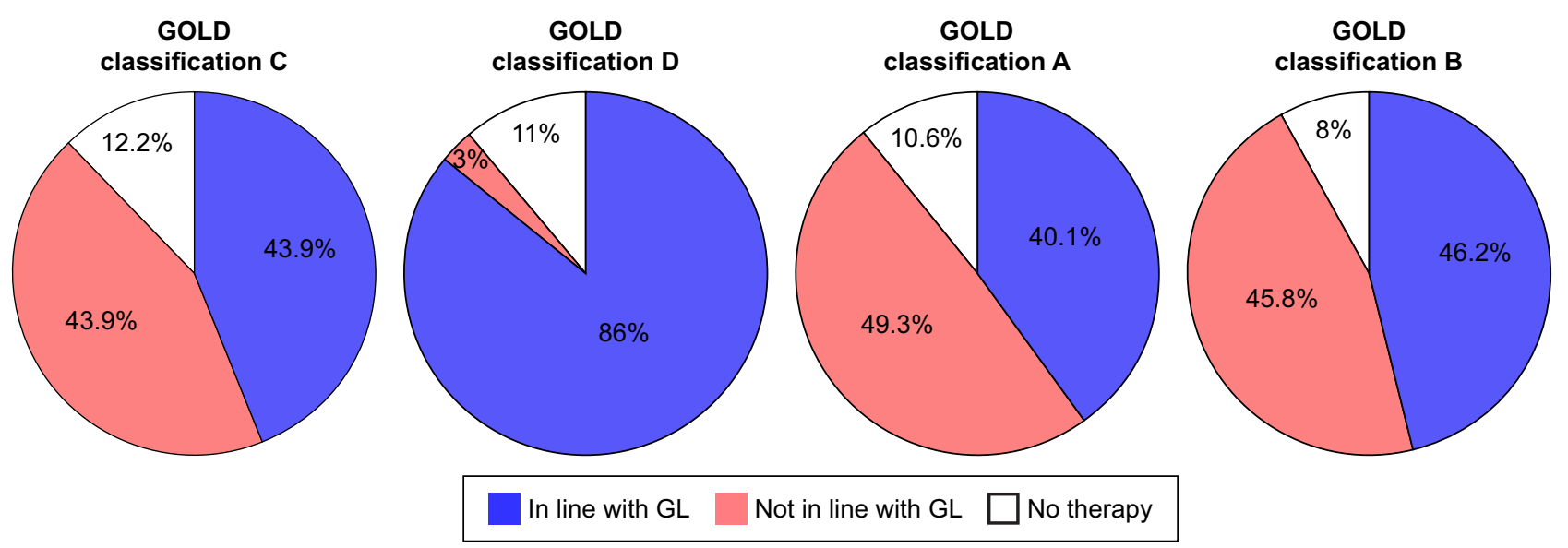

Figure 2 Assessment of the degree of therapeutic appropriateness of the study population classified by severity classes in relation to the GOLD 2015 guidelines. Abbreviations: GL, guidelines; GOLD, Global initiative for chronic Obstructive Lung Disease.

specializing in market research and statistical analysis) only $14 \%$ of Italians know what COPD is, although they estimated that there are $>3$ million COPD patients in Italy who consume $\sim 9$ billion euros. However, in both cases it is discouraging to find that appropriate diagnosis or therapy

Table 4 Online survey results

\begin{tabular}{ll}
\hline Online survey & Percentage \\
\hline The survey showed that $30 \%$ of COPD patients did & \\
not follow the therapy suggested by GOLD. Why? & 60 \\
Guidelines far from reality & 20 \\
Guidelines are difficult to apply & 20 \\
Poor knowledge of the guidelines & \\
Why "ABCD" model is difficult to routinely use? & 40 \\
Spirometry is not always feasible & 20 \\
mMRC or CAT not always feasible & 30 \\
Increased visit time & 10 \\
Others & \\
Most discrepancies are related to the excessive use of & \\
ICS. How do you explain it? & 50 \\
Information received from pharmaceutical companies & 30 \\
The corticosteroids are more effective & 20 \\
Others & \\
Higher percentages of patients are inappropriately & \\
treated by triple therapy. Why? & 35 \\
Guarantees better and faster results on the patient's & \\
symptoms & \\
Easier to prescribe than double bronchodilation & 40 \\
Business issues & 15 \\
Others & 10 \\
Approximately I I\% of patients in Group D did & \\
not take any therapy at the time of their first visit. & \\
What are the causes? & \\
The general medical practitioner underestimates the & 45 \\
disease & \\
Patients underestimate the disease & \\
Both & \\
\hline Abrevtion & \\
\hline
\end{tabular}

Abbreviations: CAT, COPD Assessment Test; GOLD, Global initiative for chronic Obstructive Lung Disease; ICS, inhaled corticosteroids, mMRC, Modified Medical Research Council. has been delayed in these patients with severe COPD. This represents a public health problem because it is representative of a reduced awareness of the disease on the part of the resident population and on the other hand by a lack of awareness on the part of regional health institutions.

Another interesting consideration comes from the latest version of GOLD 2017.7 The new ABCD approach assesses only the symptoms and history of exacerbations separating spirometric grades with the aim to reduce confusion ${ }^{25}$ and maintain consistency and simplicity for the practicing clinics. In this context, spirometry remains vital for diagnosis. However, it is well known that deteriorating airflow limitation is associated with an increasing prevalence of exacerbations and hospitalizations. ${ }^{5}$ In this survey, we found that $25.8 \%$ of patients were in Groups C-D only for the lung function impairment. With the actual guidelines they should not be treated for their high risk of exacerbations, but this could increase the health care costs associated with hospitalizations for exacerbations.

A further consideration derives from the analysis of immunization coverage. Most acute exacerbations are triggered by community-acquired respiratory infections, and although clinical trial data are limited, vaccinations can prevent some of the infections that cause exacerbations and should be administered to all patients with COPD. ${ }^{26}$ Vaccination coverage for influenza virus and pneumococcus in the Puglia region is very low: $45.7 \%$ vaccinated for flu virus and $23.8 \%$ for pneumococcus and $22.6 \%$ for both. This is another important indicator derived from this study that could be used by policy makers to launch awareness campaigns in order to further reduce the risk of exacerbations and pneumonia in this particular group of patients.

Finally, we would underline that this study was carried out by a collaboration between the Regional Health 
Agency and pulmonologists with the purpose to provide policy makers with useful information for the implementation of appropriate regional health policy measures in order to improve appropriateness and reduce the waste of health resources. Clinical audits have emerged as an overarching tool to measure the adequacy of clinical practice in a given health care setting and temporal context and have shown their role in highlighting the gaps between the health care that patients receive and the recommended practices. ${ }^{27}$ Many of these audits have provided relevant information about medical intervention in a hospital ward. ${ }^{28-30}$

A practical way to improve the management of COPD in real life might just be the use of this web platform on an ongoing basis. The use of information and communication technologies to manage chronic diseases has already been described in the literature with good results. ${ }^{31}$ In this context, this web platform helps the clinician step by step during a medical visit, providing an automatic calculation on the questionnaires (CAT and mMRC) and on the staging of the severity of the pathology. Furthermore, the data entered are stored and made accessible to clinicians who will visit a patient who already entered into the system, allowing in real time to evaluate, for example, previous spirometry or previous number and management of exacerbations.

Finally, the results of the online survey, allowing us to know precisely the reasons behind the results obtained, could help to apply targeted measures to improve diagnostic and therapeutic appropriateness.

There were several limitations in this study. First of all, we do not know who had previously prescribed the therapy that the operator had recorded on the database. Second, the history of exacerbations was self-reported and often unverifiable with reliable documentation. Furthermore, there is no regular follow-up of these patients.

\section{Conclusion}

This study showed that clinical practice is still very different from what the international recommendations suggest. Although the judgment of the single clinician remains of central importance for the management of the patient's complexity, a greater adherence to the guidelines is required in a context of political intervention to reduce public expenditure. A collaboration between health care providers and policy makers, therefore, becomes necessary and the new informatics tools could be the key to achieving these goals.

\section{Acknowledgment}

The authors would to acknowledge M Aliani, T Ardito, E Boniello, MG Cagnazzo, G Calcagnile, A Cappabianca, R De
Tullio, V Giorgio, M Ruccia, V Picca, V Spagna, E Tedeschi, P Toma, E Tupputi, and A Vizzino who helped to organize the database and follow bureaucratic process.

\section{Disclosure}

The authors report no conflicts of interest in this work.

\section{References}

1. Ferkol TB, Schraufnagel D. The global burden of respiratory disease Ann Am Thorac Soc. 2014;11(3):404-406.

2. Toy EL, Gallagher KF, Stanley EL, et al. The economic impact of exacerbations of chronic obstructive pulmonary disease and exacerbation definition: a review. COPD. 2010;7:214-228.

3. Donaldson GC, Law M, Kowlessar B, et al. Impact of prolonged exacerbation recovery in chronic obstructive pulmonary disease. Am J Respir Crit Care Med. 2015;192(8):943-950.

4. Seemungal TA, Donaldson GC, Paul EA, Bestall JC, Jeffries DJ, Wedzicha JA. Effect of exacerbation on quality of life inpatients with chronic obstructive pulmonary disease. Am J Respir Crit Care Med. 1998;157:1418-1422.

5. Müllerova H, Maselli DJ, Locantore N, et al. Hospitalized exacerbations of COPD: risk factors and outcomes in the ECLIPSE cohort. Chest. 2015;147(4):999-1007.

6. Soler-Cataluña JJ, Martínez-García MA, RománSánchez P, et al. Severe acute exacerbations and mortality in patients with chronic obstructive pulmonary disease. Thorax. 2005;60(11):925-931.

7. Global Initiative for Chronic Obstructive Lung Disease (GOLD). Global Strategy for the Diagnosis, Management, and Prevention of Chronic Obstructive Pulmonary Disease; updated. 2015. Available from: http://www.msc.es/organizacion/sns/planCalidadSNS/pdf/GOLD_ Report_2015_Apr2.pdf. Accessed August 1, 2018.

8. Tashkin DP, Celli B, Senn S, et al. A 4-year trial of tiotropium in chronic obstructive pulmonary disease. N Engl J Med. 2008;359:1543-1554.

9. Calverley PM, Anderson JA, Celli B, et al. Salmeterol and fluticasone propionate and survival in chronic obstructive pulmonary disease. N Engl J Med. 2007;356(8):775-789.

10. Wedzicha JA, Buhl R, Lawrence D, Young D. Monotherapy with indacaterol once daily reduces the rate of exacerbations in patients with moderate-to-severe COPD: post-hoc pooled analysis of 6 months data from three large phase III trials. Respir Med. 2015;109(1): $105-111$.

11. Wedzicha JA, Calverley PM, Seemungal TA, et al. The prevention of chronic obstructive pulmonary disease exacerbations by salmeterol/ fluticasone propionate or tiotropium bromide. Am J Respir Crit Care Med. 2008;177:19-26.

12. The Medicines Utilization Monitoring Centre. L'uso dei Farmaci in Italia. Rapporto Nazionale Anno 2016. Roma: Agenzia Italiana del Farmaco, 2017. [National Report on Medicines use in Italy. JanuarySeptember 2016. Rome: Italian Medicines Agency, 2017]. Available from: http://www.agenziafarmaco.gov.it/sites/default/files/Rapporto_ OsMed_2016_AIFA.pdf. Accessed August 1, 2018. Italian.

13. Asche CV, Leader S, Plauschinat C, et al. Adherence to current guidelines for chronic obstructive pulmonary disease (COPD) among patients treated with combination of long-acting bronchodilators or inhaled corticosteroids. Int J Chron Obstruct Pulmon Dis. 2012;7:201-209.

14. Chiang CH, Liu SL, Chuang CH, Jheng YH. Effects of guidelineoriented pharmacotherapy in patients with newly diagnosed COPD: a prospective study. Wien Klin Wochenschr. 2013;125(13-14):353-361.

15. Roche N, Lepage T, Bourcereau J, Terrioux P. Guidelines versus clinical practice in the treatment of chronic obstructive pulmonary disease. Eur Respir J. 2001;18(6):903.e90.

16. Miravitlles M, Sicras A, Crespo C, et al. Costs of chronic obstructive pulmonary disease in relation to compliance with guidelines: a study in the primary care setting. Ther Adv Respir Dis. 2013;7(3): 139-150. 
17. Chan KP, Ko FW, Chan HS, et al. Adherence to a COPD treatment guideline among patients in Hong Kong. Int J Chron Obstruct Pulmon Dis. 2017;12:3371-3379.

18. Ramsey SD. Suboptimal medical therapy in COPD: exploring the causes and consequences. Chest. 2000;117(2 suppl):33S-37S.

19. Turan O, Emre JC, Deniz S, Baysak A, Turan PA, Mirici A. Adherence to current COPD guidelines in Turkey. Expert Opin Pharmacother. 2016; 17(2):153-158.

20. Cabana MD, Rand CS, Powe NR, et al. Why don't physicians follow clinical practice guidelines? A framework for improvement. JAMA. 1999; 282(15):1458-1465.

21. Lucas AE, Smeenk FW, Smeele IJ, van Schayck CP. Overtreatment with inhaled corticosteroids and diagnostic problems in primary care patients, an exploratory study. Fam Pract. 2008;25(2):86-91.

22. Desalu OO, Onyedum CC, Adeoti AO, et al. Guideline-based COPD management in a resource-limited setting - physicians' understanding, adherence and barriers: a cross-sectional survey of internal and family medicine hospital-based physicians in Nigeria. Prim Care Respir J. 2013;22(1):79-85.

23. Sin DD, Man SF. Steroids in COPD: still up in the air? Eur Respir J. 2010;35:949-951.

24. Kaur I, Aggarwal B, Gogtay J. Understanding perception of chronic obstructive pulmonary disease among general practitioners, physicians, and pulmonologists in India: results from a face-to-face survey. Perspect Clin Res. 2016;7(2):100-105.

25. Han MK, Muellerova H, Curran-Everett D, et al. GOLD 2011 disease severity classification in COPD Gene: a prospective cohort study. Lancet Respir Med. 2013;1(1):43-50.

26. Varkey JB, Varkey AB, Varkey B. Prophylactic vaccinations in chronic obstructive pulmonary disease: current status. Curr Opin Pulm Med.2009; 15(2):90-99.
27. Ivers NM, Grimshaw JM, Jamtvedt G, et al. Growing literature, stagnant science? Systematic review, meta-regression and cumulative analysis of audit and feedback interventions in health care. J Gen Intern Med. 2014;29(11):1534-1541.

28. Roberts CM, Lopez-Campos JL, Pozo-Rodriguez F, Hartl S; European COPD Audit team. European hospital adherence to GOLD recommendations for chronic obstructive pulmonary disease (COPD) exacerbation admissions. Thorax. 2013;68(12):1169-1171.

29. Lopez-Campos JL, Hartl S, Pozo-Rodriguez F, Roberts CM. Variability of hospital resources for acute care of COPD patients: the European COPD Audit. Eur Respir J. 2014;43(3):754-762.

30. Pozo-Rodriguez F, Castro-Acosta A, Alvarez CJ, et al. Determinants of between-hospital variations in outcomes for patients admitted with COPD exacerbations: findings from a nationwide clinical audit (AUDIPOC) in Spain. Int J Clin Pract. 2015;69(9):938-947.

31. Velickovski F, Ceccaroni L, Roca J, et al. Clinical Decision Support Systems (CDSS) for preventive management of COPD patients. J Transl Med. 2014;12(suppl 2):S9.

32. Wei YF, Kuo PH, Tsai YH, et al. Factors associated with the prescription of inhaled corticosteroids in GOLD group A and B patients with COPD - subgroup analysis of the Taiwan obstructive lung disease cohort. Int J Chron Obstruct Pulmon Dis. 2015;10:1951-1956.

33. de Miguel-Diez J, Carrasco-Garrido P, Rejas-Gutierrez J, et al. Inappropriate overuse of inhaled corticosteroids for COPD patients: impact on health costs and health status. Lung. 2011;189(3):199-206.

34. White P, Thornton H, Pinnock H, Georgopoulou S, Booth HP. Overtreatment of COPD with inhaled corticosteroids - implications for safety and costs: cross-sectional observational study. PLoS One. 2013; 8(10): 75221 .

35. Corrado A, Rossi A. How far is real life from COPD therapy guidelines? An Italian observational study. Respir Med. 2012;106(7):989-997.
International Journal of COPD

\section{Publish your work in this journal}

The International Journal of COPD is an international, peer-reviewed journal of therapeutics and pharmacology focusing on concise rapid reporting of clinical studies and reviews in COPD. Special focus is given to the pathophysiological processes underlying the disease, intervention programs, patient focused education, and self management protocols.

\section{Dovepress}

This journal is indexed on PubMed Central, MedLine and CAS. The manuscript management system is completely online and includes a very quick and fair peer-review system, which is all easy to use. Visit http://www.dovepress.com/testimonials.php to read real quotes from published authors. 